\title{
ESPORTE UNIVERSITÁRIO, FLAG E LAZER SÉRIO ${ }^{1}$
}

Recebido em: $12 / 12 / 2017$

Aceito em: 01/08/2018

\author{
Bianca Inácio da Luz Ferreira \\ Olívia Cristina Ferreira Ribeiro \\ Universidade Estadual de Campinas (UNICAMP) \\ Campinas - SP - Brasil
}

\begin{abstract}
RESUMO: A Perspectiva do Lazer Sério é um viés importante para compreensão do esporte universitário no tempo livre. Ela determina que praticantes de lazer sério apresentem persistência, carreira, empenho, benefícios duráveis, ethos único e identificação com uma prática de lazer. O flag - prática derivada do futebol americano, um dos esportes que mais se populariza no Brasil na atualidade - é praticado por atletas brasileiros também em nível universitário. Os objetivos desse estudo foram verificar a presença das qualidades do lazer sério nos atletas de flag do time masculino Eucalyptus Unicamp e verificar a importância do esporte em suas vidas. Este estudo de caso coletou dados por meio de observação, questionário, Inventário de Medidas em Lazer Sério e entrevistas. Os resultados apontam que as qualidades estão presentes no relacionamento atleta/flag, além de demonstrar a centralidade do esporte na vida dos participantes.
\end{abstract}

PALAVRAS CHAVE: Atividades de Lazer. Lazer Sério. Esporte Universitário. Flag.

\section{COLLEGE SPORTS, FLAG FOOTBALL AND SERIOUS LEISURE}

ABSTRACT: The Serious Leisure Perspective is an interesting bias for understanding college sports in Brazil and free time. It determines that serious leisure practitioners present persistence, career, effort, durable benefits, unique ethos and identification with the pursuit. The flag - practice derived from Football, one of the most popular sports in Brazil nowadays - is practiced by Brazilians also at college level. The objectives of this study were to verify the presence of serious leisure qualities in the relationship athletes of the Eucalyptus Unicamp men's team have with the sport and verify the importance of flag in their lives. This case study collected data through observation, questionnaire, Serious Leisure Inventory and Measure and interviews. The results point out that the qualities are present in the athlete/flag relationship, besides it was demonstrated the centrality of the sport in the participants' lives.

KEYWORDS: Leisure Activities. Serious Leisure. College Sports. Flag Football.

\footnotetext{
${ }^{1}$ Este estudo teve apoio financeiro do CNPq.
} 


\section{Introdução}

O futebol americano é uma modalidade esportiva coletiva desenvolvida nos Estados Unidos no século XIX, com base nos esportes ingleses rúgbi e futebol. Em oposição ao eurocentrismo vigente no período, ideais da cultura americana foram agregados no desenvolvimento do futebol americano, para que ele se consolidasse como o esporte mais popular em seu país de origem. Para tal, foi necessário que o jogo se tornasse mais atrativo aos praticantes, ao público e aos investidores. Dessa forma, o impulso para as mudanças realizadas na modalidade foi o grande investimento financeiro e a venda do esporte como um espetáculo e representação do estilo de vida americano pelas transmissões televisivas (CURTI, 2016).

Semelhante ao que ocorreu nos Estados Unidos, o futebol americano também se populariza no Brasil por meio dos meios de comunicação, especialmente com a TV a cabo e a internet. O esporte é um dos que mais crescem entre os brasileiros na atualidade e, em relação ao que é consumido no Brasil, a tendência é que seja o mesmo que é consumido nos Estados Unidos. Porém, se consideradas as possibilidades de prática no contexto brasileiro, existe o problema da inacessibilidade aos equipamentos, que são caros, além do despreparo físico dos brasileiros para a intensidade da modalidade (MERLO, 2005).

A alternativa para se contornar esse entrave seria a prática do flag ${ }^{2}$, modalidade na qual, é possível se experienciar as principais situações do futebol americano, porém com menor risco de lesões e com baixo custo (PERFEITO et al., 2012). Dessa forma, devido à facilidade de acesso, o flag tende a se popularizar no Brasil.

\footnotetext{
${ }^{2}$ Modalidade esportiva coletiva derivada do futebol americano tradicional. Seu nome original é flag football, e será tratada nessa pesquisa como flag.
} 
Um exemplo de equipe praticante de flag, é o Eucalyptus Unicamp. O time foi criado em 2011 por alunos da Unicamp (UNICAMP NOTÍCAS, 2017) e disputam o flag em nível estadual e em competições universitárias. Esse time se vincula à Liga das Atléticas da Unicamp (LAU) e não é uma equipe profissional, porque os atletas são estudantes, não recebem bolsas de estudos e não têm suporte financeiro externo. Porém, isso não significa que não exista comprometimento, cobrança e desenvolvimento de um nível de desempenho satisfatório entre os praticantes.

Considerando esse panorama, esse trabalho se justifica quanto à escassez de pesquisas em futebol americano e flag no Brasil, assim como na necessidade de investigação e caracterização científica do tipo envolvimento dos atletas universitários da Unicamp com esportes. Tal caracterização se dará por meio de um referencial teórico pouco utilizado no Brasil denominado Lazer Sério (STEBBINS, 2016).

Assim, pretendeu-se analisar, nesse estudo, se os atletas de flag do time masculino Eucalyptus Unicamp apresentam as qualidades distintivas do lazer sério em seu relacionamento com a modalidade, por meio do Inventário de Medidas em Lazer Sério (GOULD et al., 2008). Ademais, foi identificado a importância do flag na vida dos participantes.

\section{Metodologia}

Este estudo de caso é a combinação de pesquisa bibliográfica e exploratória (GOMES, 2005; MARCONI e LAKATOS, 2002) e integrou as abordagens quantitativa e qualitativa.

De acordo com Gomes (2005), um estudo de caso é um tipo de pesquisa que busca a análise detalhada do objeto estudado, com uso de diferentes técnicas de coleta 
de dados para uma análise satisfatória. Nesse trabalho, a coleta de dados se deu por meio de observação não participante, a aplicação de questionário e inventário e entrevistas semiestruturadas.

A pesquisa bibliográfica é efetivada a partir do levantamento de toda referência teórica publicada quanto ao tema estudado. Sua finalidade, de acordo com Marconi e Lakatos (2002) é permitir o contato direto do pesquisador com tudo que foi escrito, dito ou filmado sobre determinado assunto. É necessária, também, a realização de uma análise crítica das publicações, a fim de que se chegue a novos enfoques, abordagens ou conclusões inovadoras acerca da temática trabalhada (MARCONI e LAKATOS, 2002).

Quando exploratória, a pesquisa visa proporcionar uma compreensão geral e familiarização do pesquisador com o objeto. Nesse processo, a abordagem é descritiva e é realizado o levantamento dos estudos anteriores sobre o tema seguido do planejamento da estratégia de estudo a respeito da temática. Essa parte é o primeiro passo para o aprofundamento do trabalho em um estudo de caso (GOMES, 2005).

A determinação da modalidade participante se deu com o levantamento de todas as equipes vinculadas à Liga das Atléticas da Unicamp (LAU), seguido da apresentação da proposta de pesquisa ao técnico e dirigentes do Eucalyptus Unicamp. Houve o aceite para participação e autorização do contato da pesquisadora com os atletas.

A partir disso, foi dado início ao processo de autorização para coleta de dados no Comitê de Ética em Pesquisa da Unicamp. O projeto foi aprovado com o parecer $\mathrm{n}^{\mathrm{o}}$ 1.799.767 e o Certificado de Apresentação para Apreciação Ética (CAAE) 60820816.7 .0000 .5404 . 
Esse trabalho começou a ser desenvolvido com uma pesquisa bibliográfica com ênfase em lazer sério. Não houve delimitação temporal para o levantamento das publicações da área devido à quantidade reduzida de trabalhos sobre a temática.

Assim que foi obtida a aprovação do comitê de ética, durante o segundo semestre de 2016, foram iniciadas as observações não participantes às quintas-feiras no campo de futebol da Faculdade de Educação Física da Unicamp, local no qual os treinos se desenvolviam. A utilização de observações acontece para que se estude o comportamento das pessoas em dado contexto (GOMES, 2005).

Nesse mesmo período observacional, foram aplicados, em dois encontros, o questionário e o inventário em 25 atletas disponíveis para participação voluntária nesse estudo e, por isto, a amostra foi caracterizada como aleatória (GOMES, 2005).

O questionário visou coletar dados sobre o perfil dos voluntários. Foram levantadas questões pessoais como idade, local de trabalho e/ou estudo, bem como sua relação com o flag: quando e como conheceu o flag, onde e quando começou a participar da modalidade, por que pratica o esporte, entre outras.

O Inventário de Medidas em Lazer Sério desenvolvido por Gould et al. (2008), com 54 itens recolheu o nível de participação dos sujeitos nas seis qualidades distintivas que caracterizam uma atividade como Lazer Sério com uma escala Likert de cinco pontos. O instrumento original foi traduzido para o português pelas pesquisadoras.

Nesses dias de coleta de dados foram apresentadas, aos atletas, as informações relevantes sobre a pesquisa, foram entregues e recolhidos os termos de Consentimento Livre e Esclarecido (TCLE) assinados de cada indivíduo e foi aplicado o Inventário de Medidas em Lazer Sério (GOULD et al., 2008) e o questionário. Os instrumentos estavam impressos e a pesquisadora sanou todas as dúvidas existentes. 
Os dados recolhidos foram tabulados e organizados em gráficos em uma planilha de Excel e, partir disso, foram escolhidos cinco possíveis voluntários para a fase de entrevista, caracterizando tal amostra como intencional. Eles foram contatados e quatro selecionados foram entrevistados individualmente. Cada encontro foi gravado em áudio com o auxílio de um smartphone e, posteriormente, as gravações foram transcritas em documentos do Word.

Entrevista é, de acordo com Gomes (2005), uma conversa intencional que visa recolher informações específicas sobre um assunto. No caso desse estudo, as entrevistas foram semiestruturadas, o que significa que existiu um roteiro prévio com perguntas abertas. Tal roteiro foi baseado nas perguntas do inventário e do questionário. Buscouse compreender se o flag é significativo na vida do atleta, além de se obter a descrição qualitativa da participação do sujeito nas seis qualidades distintivas do lazer sério.

A análise de dados qualitativos - questionário e entrevistas - foi feita por análise temática. De acordo com Minayo e Gomes (2012), nesse tipo de análise o conceito central é o tema, e este comporta um leque de relações. Bardin (2011) também indica que é possível que a investigação se paute em temas centrais e, para determinação de tais temas, as ideias que se repetem no texto são recortadas, categorizadas e organizadas nos temas, para que a partir deles interpretações e inferências sejam feitas no material. Os temas levantados foram referentes às dimensões do lazer sério (1999).

Quanto à análise dos dados do Inventário, caracterizados como quantitativos, os valores obtidos foram classificados em níveis intervalares e suas modas foram detectadas e interpretadas. Levin (1987) afirma que a obtenção da moda se dá pelos escores que ocorrem com maior frequência em uma distribuição de dados. 


\section{O lazer para Stebbins}

O lazer na Perspectiva do Lazer Sério (PLS) de Stebbins (2016) é entendido como fruto da cultura. As atividades de lazer são escolhidas livremente e são vivenciadas no tempo livre de obrigações não prazerosas - lazer e trabalho se relacionam e não se opõe. O indivíduo estaria físico ou mentalmente motivado pela esperança de alcançar algum fim com tal atividade (STEBBINS, 2016).

Stebbins (2016) frisa que atividades do tempo de lazer que acontecem por coação, não devem ser consideradas, além de que a atividade de lazer sempre demandará cumprimento de metas que se alcance algum objetivo e se obtenha satisfação. Tal satisfação pode se dar pela prática da atividade em si e também pelos objetivos alcançados em longo prazo.

O mesmo autor afirma que, além da caracterização geral do que é o lazer, devese considerar o que, de fato, está sendo feito no tempo livre das pessoas. Dessa forma, a PLS se torna uma alternativa para a compreensão desse fenômeno, já que ela considera uma gama variada de atividades de lazer. Ele também coloca que a PLS oferece diversos componentes para se estudar o lazer no Brasil, especialmente sobre as atividades que são levadas a sério (STEBBINS, 2016).

\section{Lazer Sério}

Stebbins é um estudioso do lazer responsável pelo desenvolvimento da Perspectiva do Lazer Sério. Tal perspectiva ainda é pouco utilizada no Brasil, e pode ser entendida como um arcabouço teórico que mostra as diferenças, similaridades e relações de três formas principais de lazer: o Lazer Sério (LS) / Trabalho Devotado (TD), o Lazer Casual (LC) e o Lazer Baseado em Projeto (LBP). Além disso, a PLS considera o 
contexto histórico, cultural e social nas quais as diversas atividades estão inseridas para o seu estudo (STEBBINS, 2016).

Segundo Oliveira e Doll (2012, p.3), o LS se refere à:

[...] uma atividade prática sistematizada, na qual amadores, voluntários e praticantes de hobbies se envolvem para desenvolverem uma carreira de lazer, com a finalidade de adquirir e expressar uma combinação de habilidades especiais, conhecimentos e experiências.

O trabalho com devoção está na mesma categoria que o LS, e é definido como um tipo de trabalho formal que é tão atrativo, que em sua essência, pode ser considerado lazer (STEBBINS, 2016).

O lazer casual, por sua vez, é entendido como "uma atividade imediata, de valor intrínseco, com satisfação relativamente curta, que requer pouca ou nenhuma habilidade especial para ser aproveitada" (OLIVEIRA e DOLL, 2012, p.5) como, por exemplo, jogos, relaxamento, entretenimentos ativo e passivo ou conversação social.

Por outro lado, o lazer baseado em projeto pode ser entendido como uma festa de aniversário ou evento comemorativo de uma empresa e por definição ele é:

Uma tarefa criativa, excepcional ou ocasional, pouco frequente, no tempo livre, que requer planejamento e esforço consideráveis e, algumas vezes, habilidades e conhecimento, mas em que, diferente do 'lazer sério', não há a intenção pelos participantes em se desenvolver nisso (OLIVEIRA e DOLL, 2012, p.6).

Ao diferenciar as três possibilidades de prática de lazer, Stebbins (1999) explica que existem seis qualidades distintivas para categorizar o envolvimento do participante em atividades de lazer sério e não em lazer casual ou baseado em projeto.

Stebbins (1999) coloca que a primeira qualidade distintiva é a perseverança, na qual o praticante deve ter a persistência para vencer ansiedade, lesões, condições 
climáticas, medo etc. Além de demonstrar que ser perseverante é um comportamento que perpassa períodos de fracassos e vitórias (GOULD et al., 2008).

A segunda qualidade é a carreira de lazer, na qual existem progressos ou regressos em seu desenvolvimento, portanto a carreira é relativa aos estágios de envolvimento, cumprimento de objetivos e mudança nos padrões de conhecimentos e habilidades do praticante na atividade (GOULD et al., 2008).

O empenho é a terceira qualidade. Gould et al. (2008) apontam que é necessário esforço significativo por parte do praticante a fim de melhorar e adquirir habilidades e conhecimentos para alcançar um nível satisfatório de desempenho.

A quarta qualidade é relativa aos benefícios duráveis que são advindos da prática da atividade de LS. Tais benefícios podem ser classificados como individuais ou sociais (GOULD et al., 2008). Os primeiros incluem: enriquecimento pessoal, autorrealização, autoexpressão individual, melhora da autoimagem, autogratificação, recriação e retorno financeiro. Os benefícios sociais são: o senso de atração coletiva, a realização coletiva e a manutenção coletiva.

Aprofundando as definições dos benefícios duráveis individuais, o enriquecimento se dá pelas sucessivas boas experiências advindas da participação no LS e os maiores ganhos seriam na esfera intelectual e espiritual do sujeito. A autorrealização é demonstrada quando o praticante expressa todo seu potencial, capacidades e talentos. A autoexpressão é ir além da simples aplicação de conhecimentos e habilidades, mas utiliza-se da prática para se expressar. A melhora da autoimagem acontece quando, na expressão de habilidades e conhecimentos, o praticante compreende a importância de suas ações individuais. A seguir, a autogratificação acontece quando os desejos da pessoa são satisfeitos, gerando diversão 
e profundo contentamento. A recriação pode significar tanto o "recrear/divertir-se", quanto pode se manifestar como potência revigoradora, regenerativa e renovadora. Por fim, os benefícios individuais acerca do retorno financeiro no LS podem ser recebimento de produtos, dinheiro ou instrução (GOULD et al., 2008).

Quanto aos benefícios duráveis relativos à esfera social, Gould et al. (2008) colocam que a atração coletiva pode ser compreendida como as recompensas sociais da participação do universo da atividade de LS. As realizações coletivas estão no esforço coletivo para o cumprimento de um objetivo e, também no sentimento de que cada um teve um papel fundamental no resultado obtido. A manutenção coletiva se dá no mesmo sentido que as realizações, já que os esforços coletivos são direcionados para que o grupo se mantenha coeso, unido e se desenvolva.

A quinta qualidade distintiva é o ethos único, o qual implica na "existência de ideais, valores, sentimentos e crenças entre os membros de um mundo social de lazer sério" (GOULD et al., 2008, p.51) - os praticantes estão imersos na subcultura da atividade de lazer.

A última qualidade do LS é a identificação com a prática. Gould et al. (2008) declaram que participantes de atividades de LS tendem a ser conhecidos pelo seu envolvimento com a atividade e se também se apresentarem como tal.

Stebbins delineia as qualidades distintivas da PLS após se deparar com diversas situações em seu trabalho de campo no lazer, nas quais os participantes de diferentes atividades declaravam que as práticas em que estavam envolvidos não poderiam ser consideradas “apenas um lazer” já que eles eram altamente comprometidos, buscavam bom desempenho e se empenhavam ao máximo para melhorar suas habilidades. Esse 
tipo de atitude pode estar presente em atividades voluntárias, hobbies e amadorismo (OLIVEIRA e DOLL, 2012).

A PLS se estende na discussão do lazer em uma gama de atividades de lazer. A figura abaixo apresenta, graficamente, todas as possibilidades consideradas na PLS.

Figura 1 - Diagrama da Perspectiva do Lazer Sério

\section{A Perspectiva do Lazer Sério (PLS)}

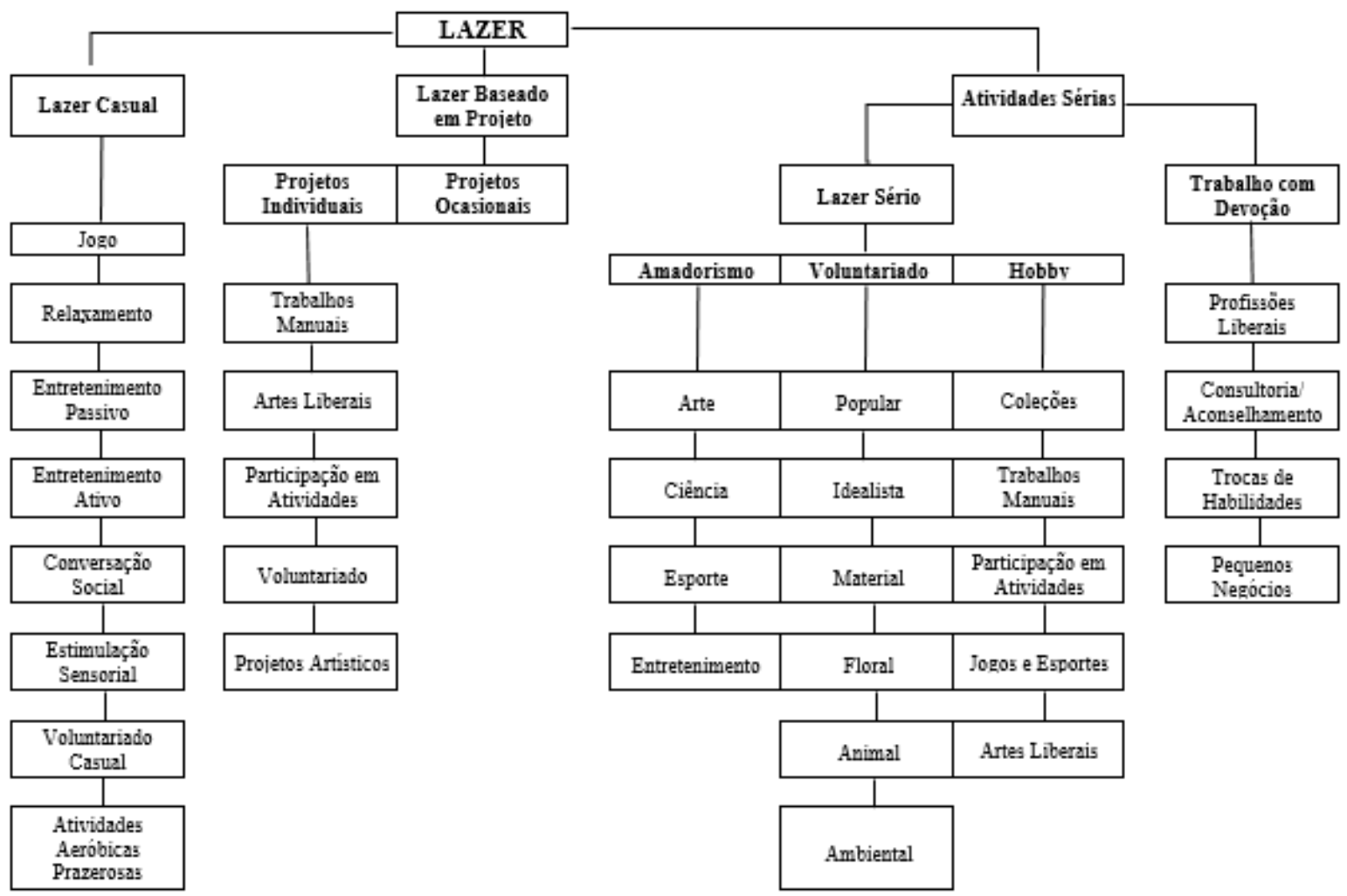

Fonte: Traduzido pelas autoras de Stebbins, 2016.

Para esta pesquisa, o ramo considerado é o do lazer sério, em atividades amadoras no esporte.

Stebbins (1979) descreve que o amador é uma pessoa inexperiente que se empenha numa atividade de arte, ciência, esporte ou entretenimento e investe muito tempo até alcançar alguma competência na prática devido à inspiração nas 
performances dos profissionais. Esses indivíduos se comprometem seriamente com o universo da atividade, em vez de deixar a prática fora de suas vidas pessoais.

Além disso, nas atividades de LS, se podem identificar os participantes estranhos, turistas, regulares e os permanentes. Os permanentes são entendidos como aqueles que se envolvem na atividade como lazer sério (STEBBINS, 2016).

Tais perfis de envolvimento com a atividade de lazer são diversos e se encontram em diferentes contextos. Se considerado o contexto de esporte amador em uma universidade, por exemplo, serão detectadas diferenças no envolvimento dos atletas participantes.

Souza (2006) afirma que existem três tipos de atletas universitários: ex-atletas profissionais que participam das equipes como lazer, atletas profissionais que recebem bolsa de estudos para participar da seleção da universidade - podem ser entendidos como trabalhadores devotados - e alunos que gostam de algum esporte e o praticam de forma assistemática e desorganizada, faltando a treinos e jogos por compromissos externos - seriam os turistas para Stebbins.

Porém, Souza (2006) não considera a possibilidade da existência de atletas universitários amadores - caracterizados como os permanentes ou regulares na PLS altamente comprometidos com uma modalidade e sua equipe, perfil que devido à experiência pessoal de uma das autoras em esporte universitário nos últimos anos, não é incomum.

\section{A Liga das Atléticas da Unicamp (LAU)}

Na década de 1990, aconteceu o Intercursos da Unicamp, competição esportiva de alunos de todos os cursos de graduação e em várias modalidades e, da necessidade 
desse evento esportivo, surgiu a presença de um corpo discente organizado para gerir as necessidades desse campeonato ${ }^{3}$. Assim, por auto-organização do corpo discente, os eventos e atividades esportivas da universidade ocorreram até agosto de 1999, sem apoio direto da reitoria. Mas, a partir dessa data, os primeiros projetos de extensão universitária foram regulamentados e oficializados o que proporcionou, na Faculdade de Educação Física da Unicamp, espaço e oportunidade para o engajamento da comunidade universitária em atividades físicas sistematizadas (SOUZA, 2006).

Assim, na década seguinte, a LAU foi criada com os objetivos de organização das competições internas da Unicamp e a preparação das seleções que representariam a universidade em jogos regionais, estaduais e nacionais.

De acordo com Souza (2006), em 2003 a Liga das Atléticas da Unicamp iniciou os projetos com apoio logístico e financeiro da reitoria para as seleções da universidade. Cinco anos depois, a LAU começou seu processo de legalização em dois anos, em 2005, ela teve sua fundação oficial.

Inicialmente, as ditas "seleções" da Unicamp existiam para promover o esporte na universidade, assim os alunos das atléticas que não ofereciam treinos de algumas modalidades poderiam fazer parte desses times. Porém, de acordo com os resultados positivos alcançados nas competições universitárias, as equipes estão, de fato, se tornando as seleções da universidade e, por isto, seletivas e convocações podem ocorrer para selecionar os talentos das modalidades.

Atualmente, a LAU gerencia as seleções da Unicamp e tem como intuito

\footnotetext{
${ }^{3}$ Informação obtida em uma conversa com o presidente da LAU, Harian Braga.
} 
A construção das equipes por meio da seleção de talentos para as modalidades, a promoção da cultura esportiva dentro do campus, a divulgação da entidade Unicamp em competições externas e a construção da identidade coletiva universitária (LAU, p.2, 2015).

As modalidades administradas pela Liga das Atléticas da Unicamp são nos naipes feminino e masculino: o atletismo, handebol, futsal, voleibol, basquetebol, natação, rúgbi, taekwondô, tênis, xadrez e tênis de mesa. Apenas para a categoria masculina há o futebol de campo (LAU, 2015).

Ademais, existem modalidades parceiras que contam com algum apoio da LAU em questões logísticas. Dentre elas estão o beisebol, futebol americano/flag, judô, jiujitsu, pólo aquático, softbol e voleibol de areia (LAU, 2015). Entre todas as equipes gerenciadas pela LAU, a selecionada para esta pesquisa foi o futebol americano/flag masculino.

\section{A História do Flag}

Para se entender a história do flag, deve-se considerar que ele é uma modalidade esportiva coletiva derivada do futebol americano e suas particularidades podem ser compreendidas pelo contexto em que foi desenvolvido.

O futebol americano foi criado em meados dos anos 1800 e foi moldado ao longo dos anos para que se tornasse a modalidade mais popular dos Estados Unidos. Inicialmente, pela distinção e separação das regras do futebol e rúgbi. Em seguida, a determinação de regras que zelam pela segurança dos atletas. E por fim, a profissionalização e venda da modalidade por meio das transmissões televisivas dos jogos realizados pela National Football League (NFL) a partir de 1922 .

O flag, por sua vez, surgiu no período da Segunda Guerra Mundial, quando militares americanos adaptaram o futebol americano tradicional para uma versão 
alternativa, adequada e mais segura para os soldados (BITTENCOURT e AMORIM, 2006). Com o fim da guerra, a nova modalidade se popularizou entre os homens que cumpriram serviço militar e, rapidamente, foi organizada e institucionalizada em ligas, associações e federações nos Estados Unidos. A primeira competição internacional de flag ocorreu no ano 2000, organizada pela recém-criada Federação Internacional de Futebol Flag (FOOTBALL BABBLE, 2016).

\section{O Flag no Brasil}

Perfeito et al. (2012) afirmam que a prática do futebol americano começou na década de 1990 nas praias do Rio de Janeiro. E em 1998, a lista online Red Zone reunia os adeptos da modalidade em um fórum de discussão.

Bittencourt e Amorim (2006) e Perfeito et al. (2012) concordam que o flag começou a ser desenvolvido no âmbito escolar brasileiro em 1999 com os professores de educação física Paulo Arcuri e Claudio Telesca, os quais o introduziram em escolas de ensino fundamental na cidade de São Paulo. No ano seguinte, foi criada a ABRAFA e Flag (Associação Brasileira de Futebol Americano e Flag), fato que impulsionou a divulgação do esporte e de cursos de capacitação gratuitos para escolas, clubes e faculdades (PERFEITO et al., 2012). O primeiro jogo universitário aconteceu em 2003, em uma partida entre Mackenzie e UNISA (Universidade de Santo Amaro) na capital paulista (BITTENCOURT e AMORIM, 2006).

\section{O Jogo de Flag}

A equipe masculina do Eucalyptus Unicamp disputa o flag $8 \times 8$, ou seja, nessa versão da modalidade os times se enfrentam com oito jogadores em campo durante a 
partida. O jogo visa a conquista do território no campo de ataque, para que se anote uma pontuação maior que o time adversário até o final do tempo de jogo. Diferente do futebol americano tradicional, no qual existe contato físico para o impedimento das jogadas de ataque, no flag, para a finalização da posse de bola do ataque, é necessário que se retire a flag do cinto do atacante em posse de bola, ou que se intercepte um passe ou o impedimento do avanço de dez jardas do adversário atacante (APFA, 2016).

Figura 1 - Cinto de flag.

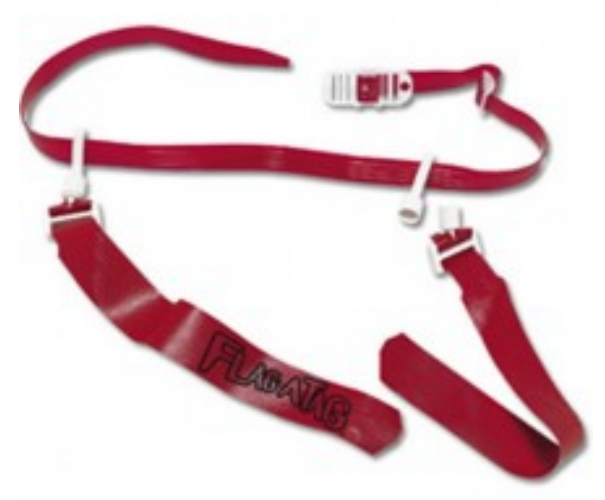

Fonte: http://portofa.com/product_images/r/945/Flag_belt_1_12826_std.jpg

\section{O Eucalyptus Unicamp}

A equipe foi criada em 2011 por alunos do Instituto de Economia (IE) da Unicamp e era praticada no 'bosquinho do IE', daí surgiu o nome do time, que se refere aos eucaliptos existentes nesse espaço (UNICAMP NOTÍCIAS, 2017).

A ideia inicial dos fundadores era que o futebol americano full pad fosse a modalidade praticada, e isso ocorreu por algum tempo, apesar da falta de materiais. Porém, o foco da equipe mudou para o flag após o Eucalyptus ter sido convidado para 
participar de um campeonato de flag organizado pela LUFA (Liga Universitária de Futebol Americano) ${ }^{4}$.

Além disso, desde o início, os fundadores e gestores da equipe se preocuparam em contratar técnicos com experiência prévia na modalidade. Parte da consolidação do time e o desenvolvimento para o patamar em que se encontram na atualidade se deve ao investimento que foi feito em material humano e esportivo ao longo dos anos.

Figura 2 - Logo da equipe Eucalyptus Unicamp

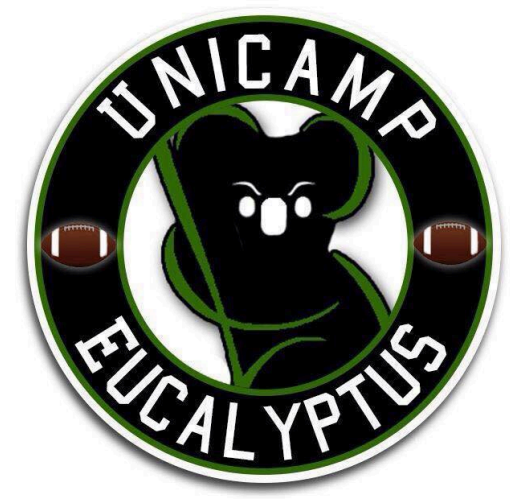

Fonte: Unicamp Notícias, 2017.

O time tem CNPJ ativo e é gerido por alunos de graduação da Unicamp. As possibilidades de prática nesta equipe são o $8 \times 8$ masculino e o $5 \times 5$ feminino.

\section{Características dos Atletas}

As respostas obtidas nos questionários são apresentadas nos gráficos abaixo.

\footnotetext{
${ }^{4}$ Informação obtida em uma conversa com o diretor financeiro da equipe, Guilherme Fogarolli.
} 
Gráfico 1: Idade dos participantes

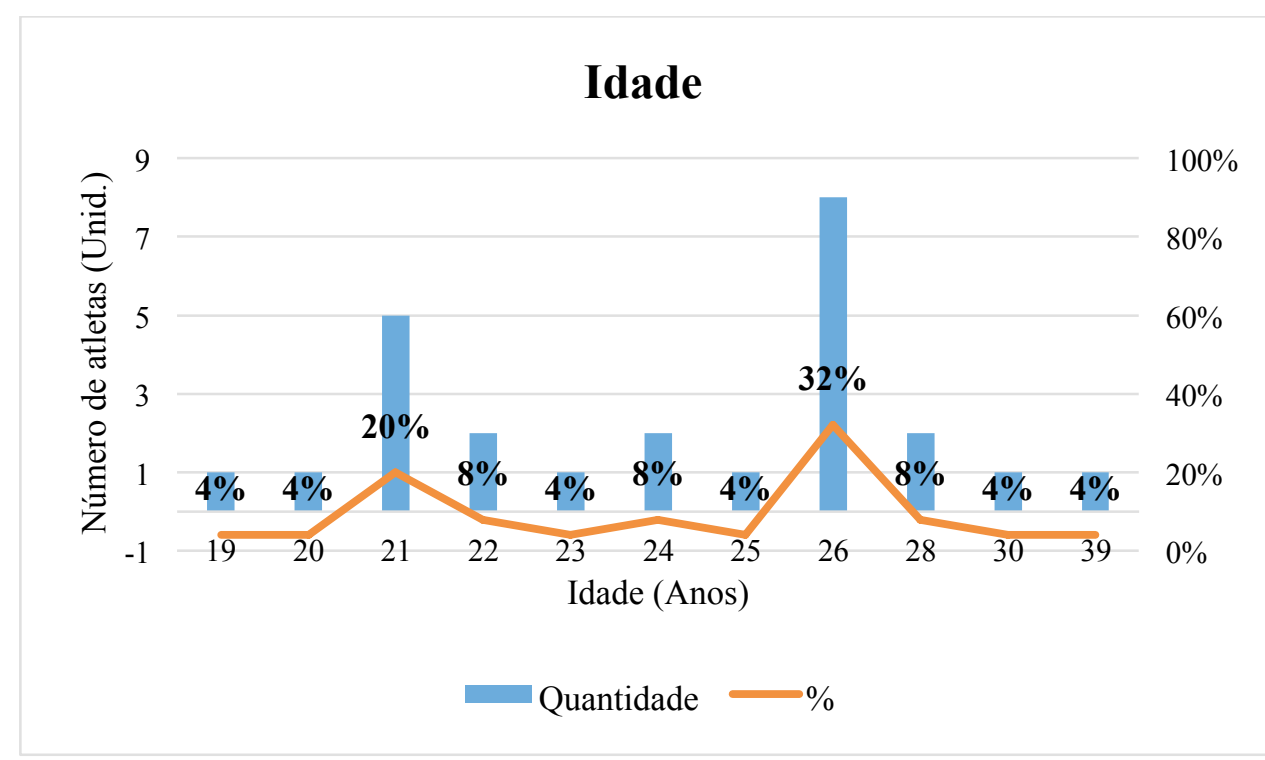

O primeiro gráfico mostra a variação da faixa etária dos atletas, que se apresentam de 19 a 39 anos. É possível observar que 32\% dos atletas tem 26 anos e $20 \%$ têm 21 anos, totalizando 13 esportistas. É interessante notar que, apesar de a equipe apresentar gerações distintas, os atletas possuem interesses comuns na prática da mesma atividade físico-esportiva, caracterizando-a como uma modalidade acessível.

Corroborando com a ideia de acessibilidade, é imprescindível apontar que assim como Stebbins (2016) afirma, a PLS traz um viés importante para a compreensão do lazer na realidade brasileira. $\mathrm{O}$ autor coloca que atividades importadas para o Brasil tendem a se modelar e se distinguir pela adição de elementos locais característicos. Isso já acontece com flag quando a versão praticada nos Estados Unidos é a 5 x 5, porém, no Estado de São Paulo, o $8 \times 8$ é o mais praticado. O entrevistado três afirma que a adaptação foi feita pela APFA e, além de ter tornado o flag mais interessante para quem assiste, devido a maior semelhança com o futebol americano tradicional, também é 
inclusivo, porque permite que pessoas de diferentes faixas etárias e tipos físicos participem da modalidade.

Gráfico 2: Atletas estudantes

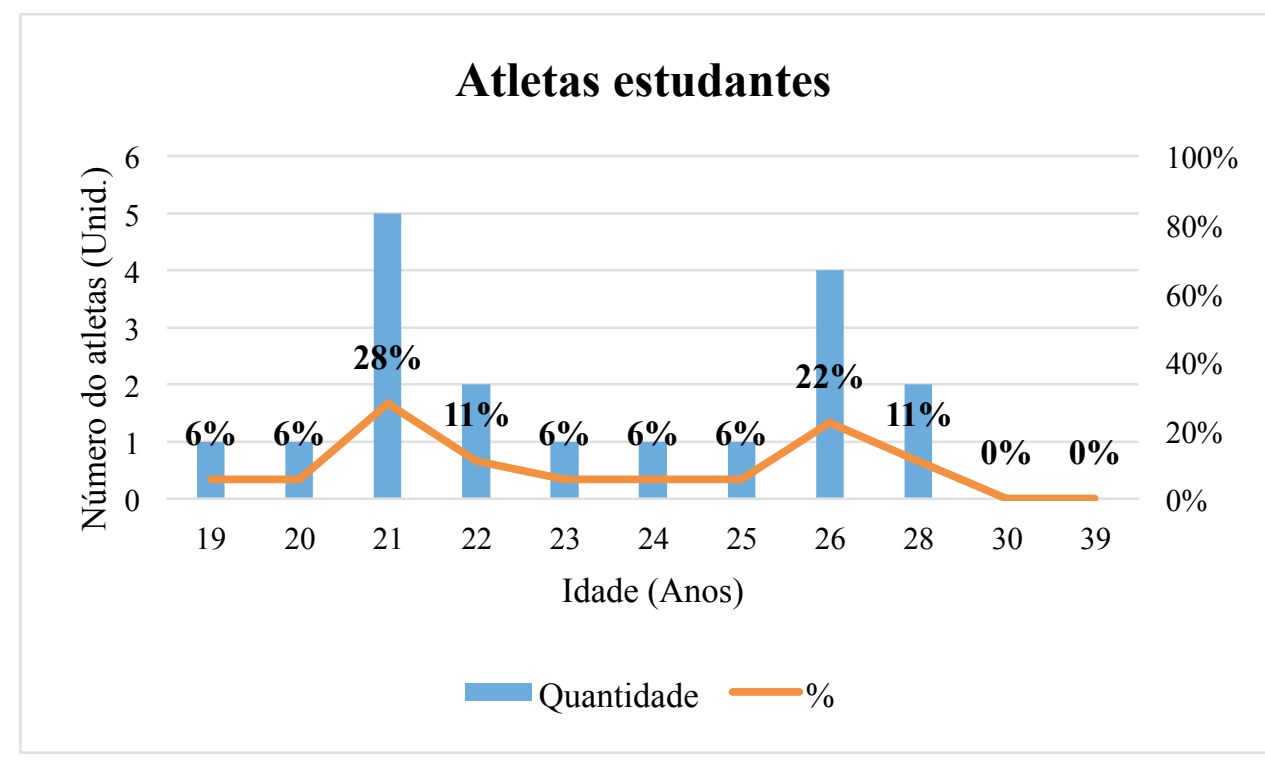

O segundo gráfico demonstra que, embora a faixa etária seja relativamente ampla - 20 anos - muitos participantes estavam inseridos em alguma instituição de ensino como estudantes.

Gráfico 3: Atletas não estudantes

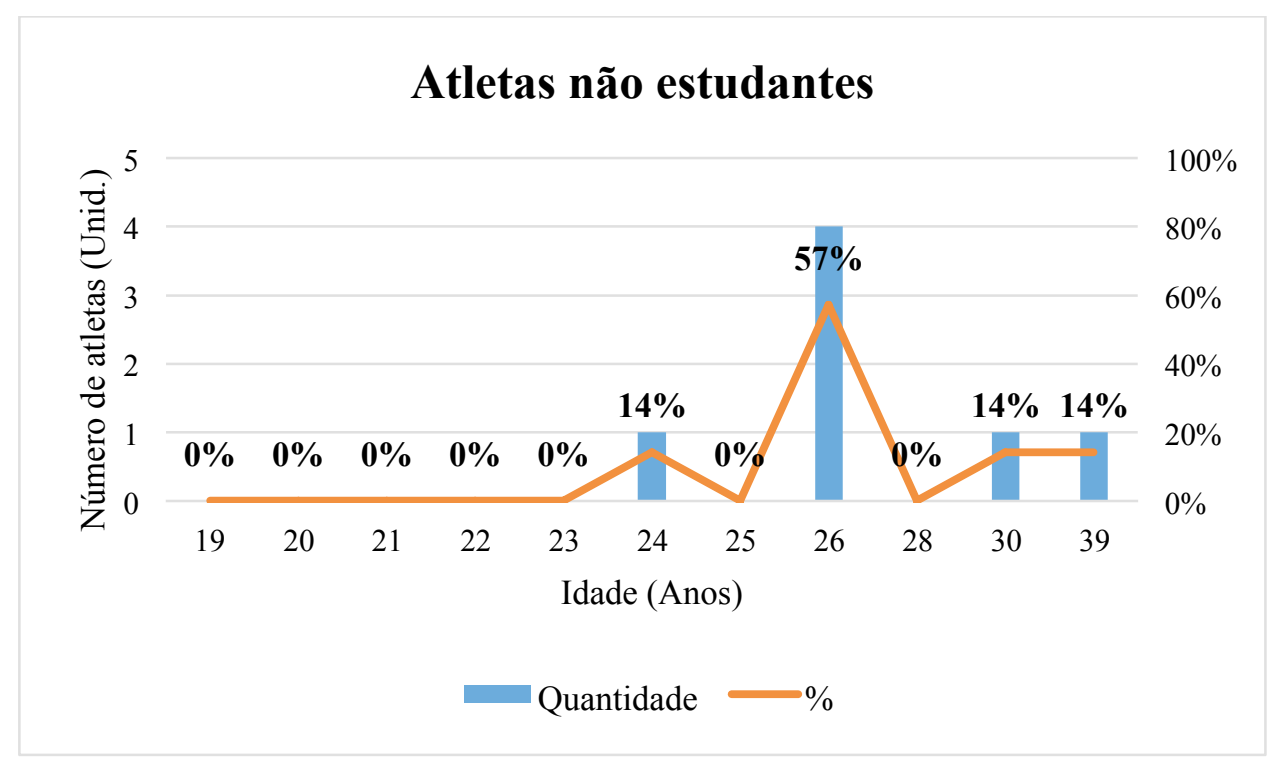


Os participantes que não se identificaram como estudantes tinham mais de 24 anos, como aponta o terceiro gráfico e a maioria, estava formada no ensino superior.

Gráfico 4: Atletas trabalhadores

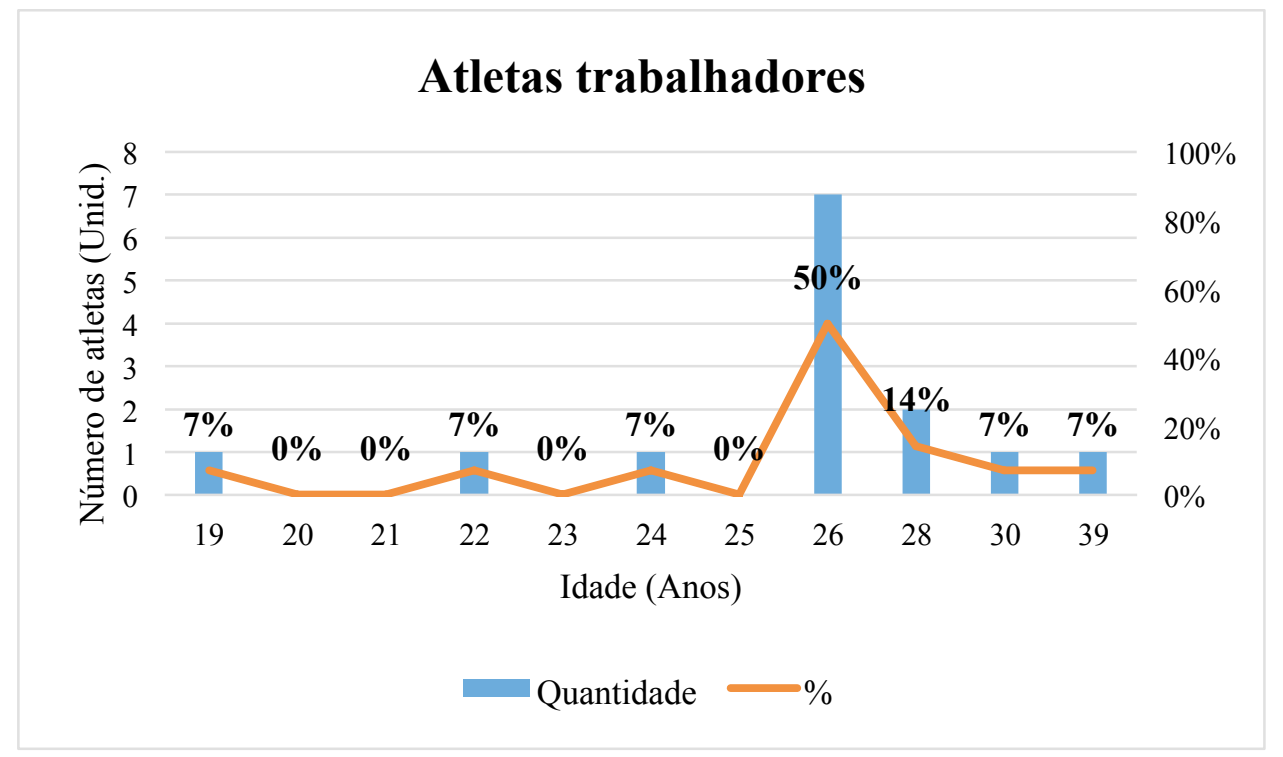

O quarto gráfico aponta que os atletas estavam inseridos no mercado de trabalho, especialmente aqueles com 26 anos ou mais, já formados no ensino superior.

Gráfico 5: Atletas não trabalhadores

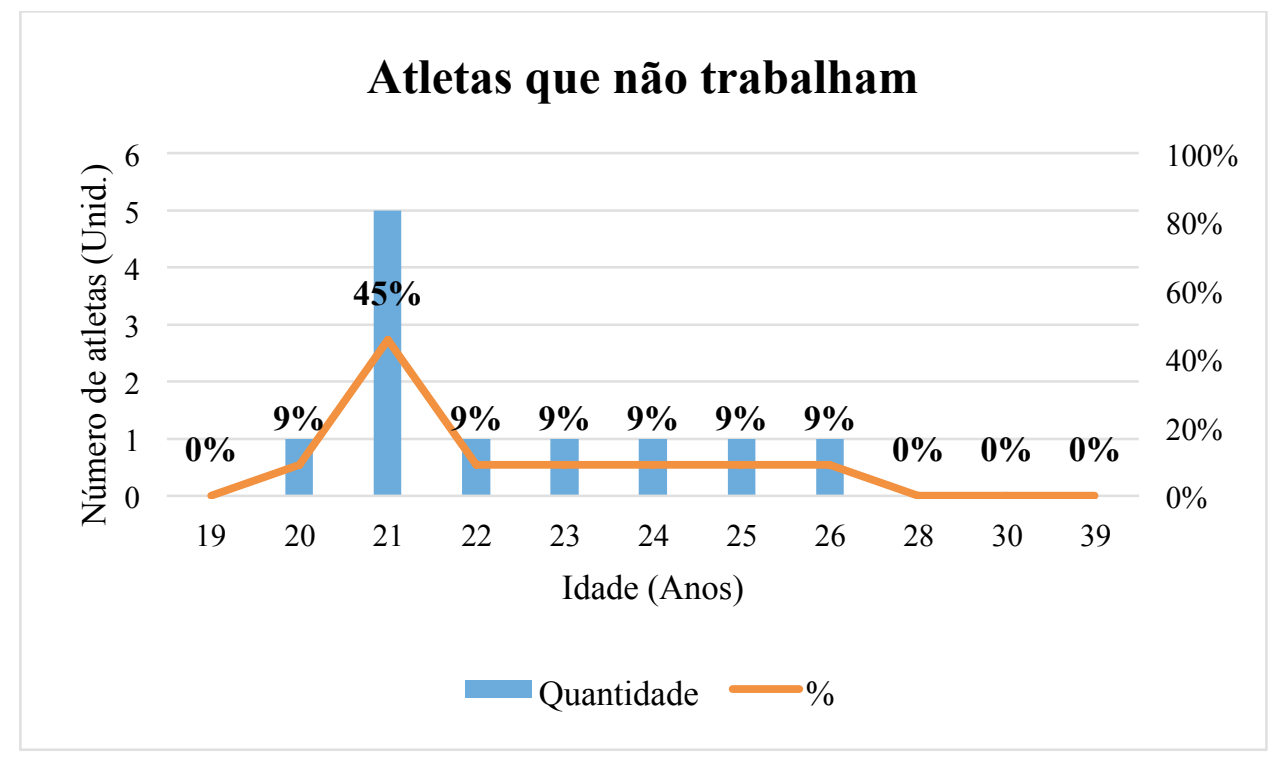


O Gráfico de número 5 se refere ao perfil dos atletas que não trabalhavam, e majoritariamente, tinham como atividade principal o estudo - como é possível notar em comparação e combinação com o Gráfico 2.

Gráfico 6: Ano de iniciação no flag

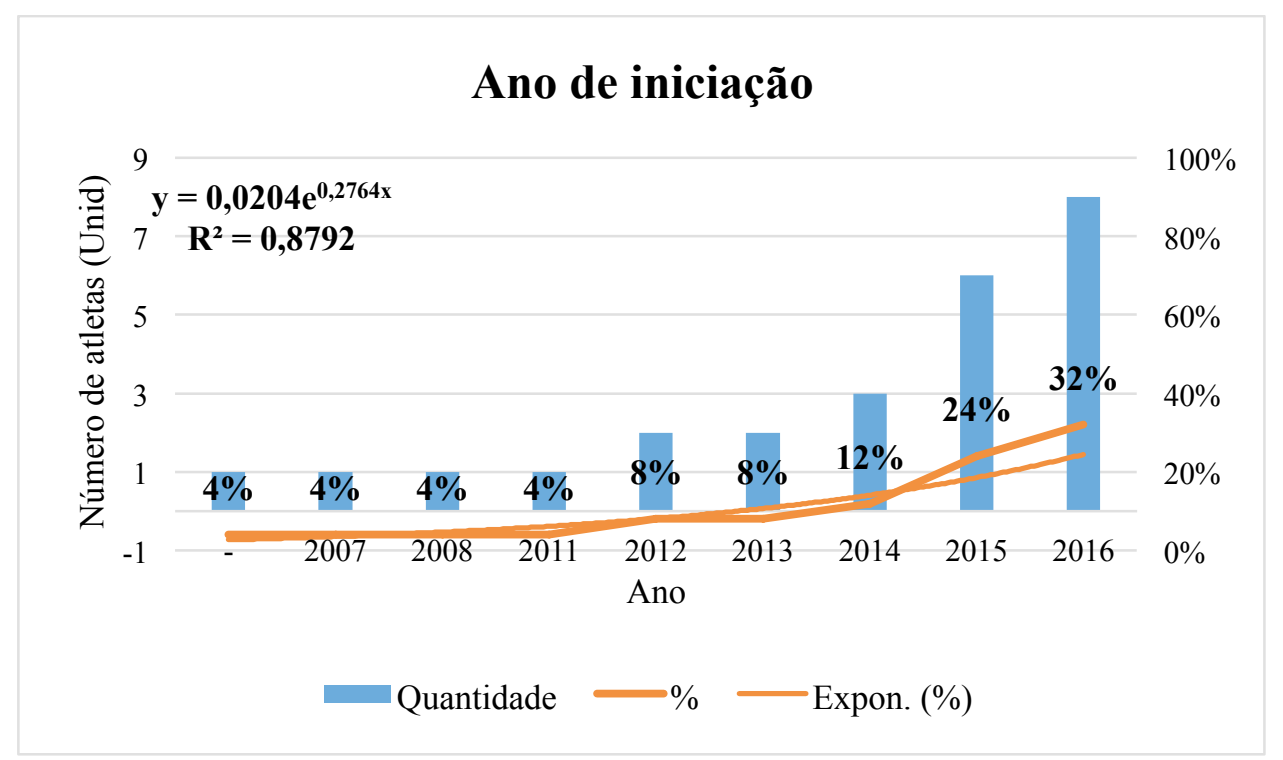

No sexto gráfico, os resultados relativos ao ano de início da prática da modalidade apontam que a grande parte dos atletas começou a treinar flag nos anos de 2016 e 2015. O gráfico indica, ainda, uma linha de tendência exponencial, que sugere o crescimento da modalidade na equipe, o que pode ser um reflexo do desenvolvimento da modalidade no Brasil. 
Gráfico 7: Práticas corporais dos participantes

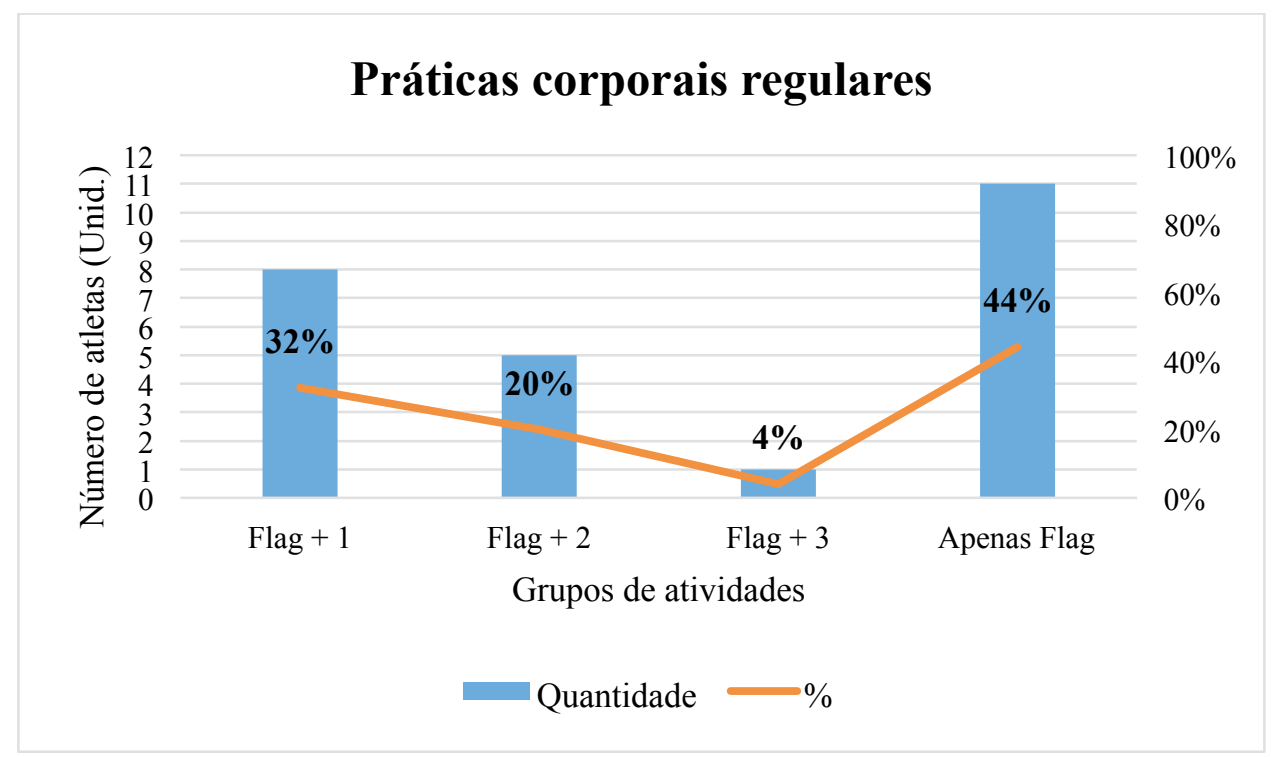

O Gráfico 7 demonstra que o flag era a prática corporal sistematizada regular principal dos voluntários. Das outras atividades que foram apontadas, as mais frequentes eram a musculação, corrida e futebol.

Como resultado da análise dos gráficos acima, podemos traçar o perfil dos participantes como segue:

Eles são estudantes adultos com idades distintas. Mais da metade dos voluntários dividem seu tempo com trabalho e estudo - ainda assim, no tempo liberado, eles se comprometem a praticar o flag e, pelo menos, mais uma atividade física com regularidade. Embora boa parte dos atletas se apresente como iniciantes na modalidade, há aqueles que já demonstram o desenvolvimento de carreira no esporte devido aos anos que passaram inseridos na prática e, coincidentemente, nesse time. 


\section{O lazer Levado a Sério}

Os resultados obtidos pelo Inventário de Medidas em Lazer Sério (GOULD et al., 2008) estão organizados nos gráficos abaixo. Cada dimensão se apresenta separadamente, para que seja mais bem compreendida.

Para tal, cada gráfico representa a soma da resposta dos atletas em cada dimensão do LS. As dimensões foram avaliadas por itens, que consistiam em uma afirmativa da qual, de acordo com o grau de concordância do voluntário, uma avaliação seria feita:

- $\quad$ Discordo totalmente $(\mathrm{DT})=1$

- $\quad$ Discordo parcialmente $(\mathrm{DP})=2$

- $\quad$ Neutro $(\mathrm{N})=3$

- $\quad$ Concordo parcialmente $(\mathrm{CP})=4$

- $\quad$ Concordo totalmente $(\mathrm{CT})=5$.

Esse tipo de avaliação é conhecido como escala Likert. Silva e Costa (2014) colocam que a tal escala é usada para se mensurar o grau de concordância de um sujeito em relação às afirmações apresentadas.

Em termos estatísticos, a escala Likert pode ser entendida como uma escala intervalar, já que apresenta tanto a ordenação das categorias - nesse caso de menos concordância para mais concordância - quanto à distância entre elas (LEVIN, 1987).

Ademais, a análise quantitativa se pautou na detecção e interpretação das modas de cada gráfico. Levin (1987) afirma que a obtenção da moda acontece pela frequência de aparições de dados de uma distribuição. 
Gráfico 8: Perseverança

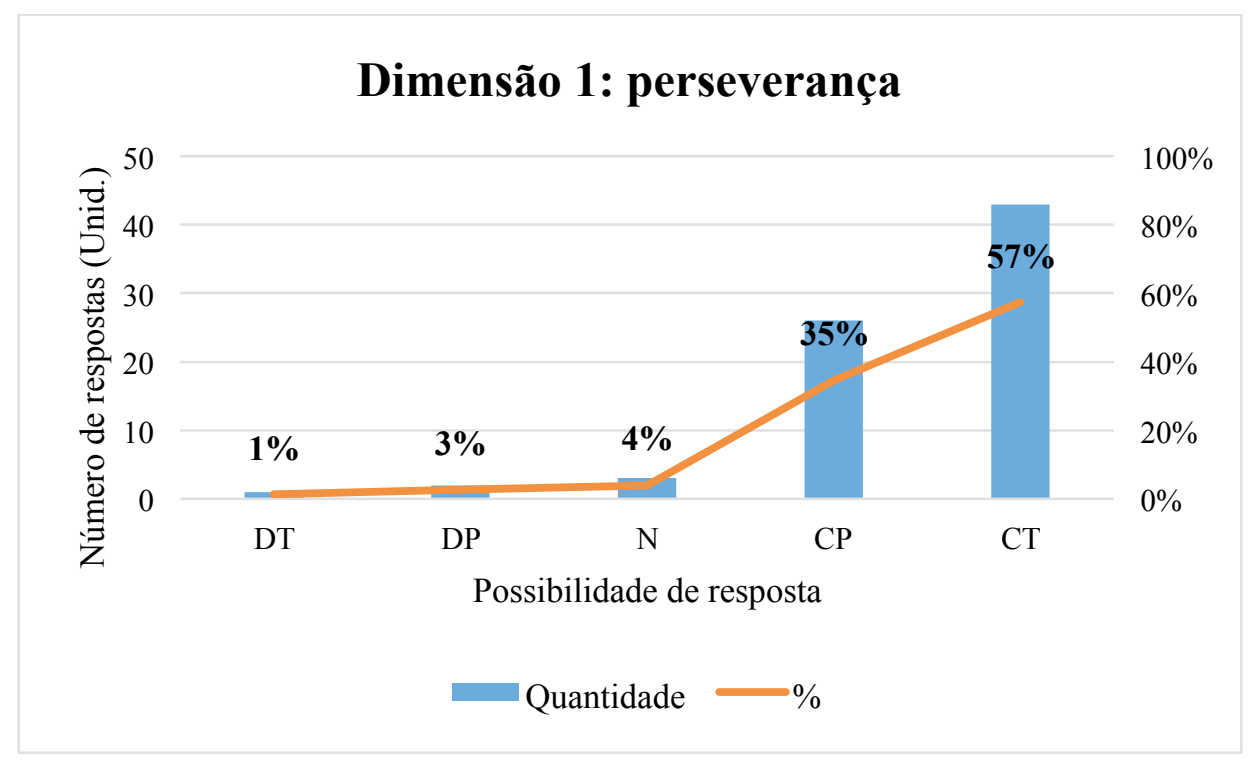

A primeira dimensão avaliou a perseverança dos atletas do Eucalyptus Unicamp.

Este grupo de perguntas avaliou se os atletas se consideravam perseverantes na prática do esporte apesar de adversidades. Assim, conforme o gráfico, é possível verificar que $92 \%$ das respostas apontam para um envolvimento consistente com a modalidade.

Todos os entrevistados afirmaram que se consideram perseverantes na prática do flag. É interessante salientar que, o relato do primeiro entrevistado está em concordância com a descrição do comportamento persistente dos praticantes de LS, no qual lesões e compromissos externos não são empecilhos para quem está focado em alcançar um objetivo de LS (GOULD et al., 2008). O primeiro entrevistado observou que:

Eu vejo o treino como uma prioridade na minha vida. Então, mesmo que eu tenha aula, eu tento mudar a aula [...] mesmo com as lesões eu continuo jogando [...] mesmo o médico determinando que eu não possa jogar, eu jogo [...] já joguei com a mão quebrada [...] a lesão não me faz parar. O time é mais prioridade que a lesão (ENTREVISTADO $1)$. 
Gráfico 9: Empenho

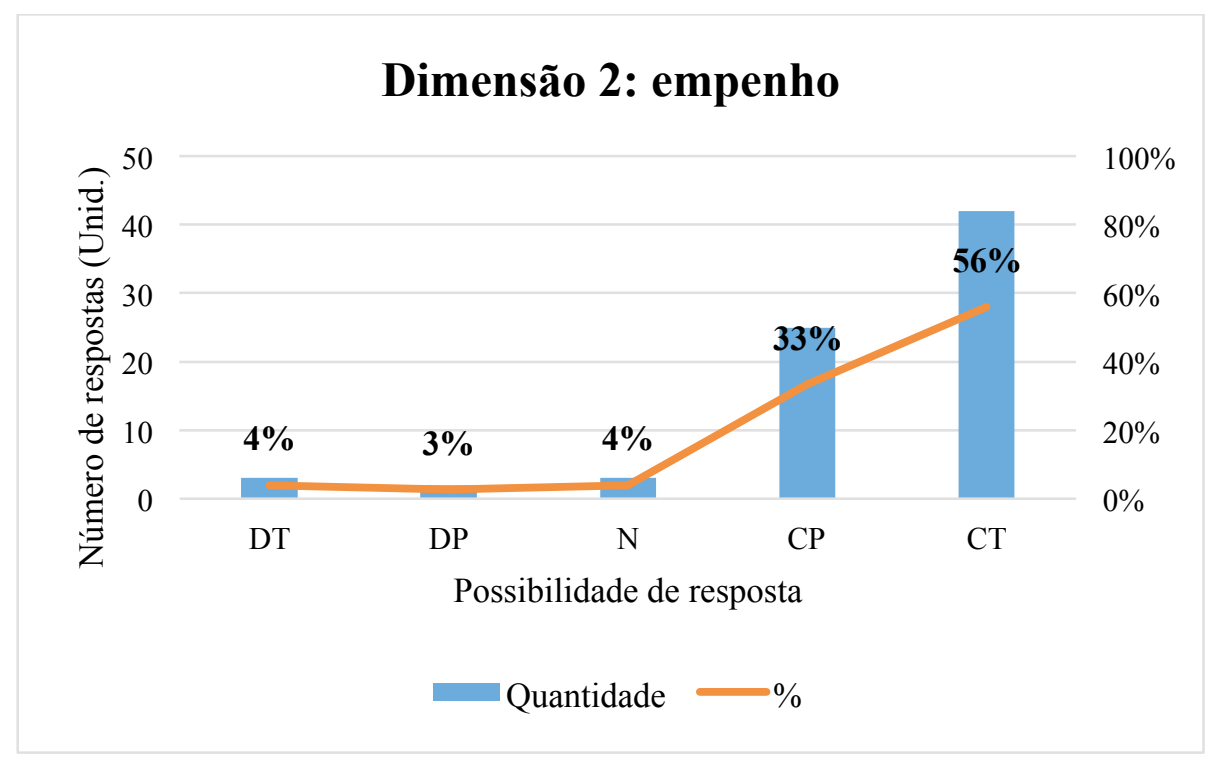

A segunda dimensão é a respeito do empenho e os itens do inventário buscavam compreender se o indivíduo se empenhava para melhorar suas habilidades do flag. $\mathrm{O}$ gráfico aponta que $86 \%$ das respostas dos atletas indicam que os mesmos investem muita energia em seu desenvolvimento na prática flag, o que corrobora com a ideia central da dimensão descrita por Stebbins (2016). Os atletas consideraram ainda que o esforço despendido, inclusive em momentos extra treino, melhorou as habilidades e competência no esporte:

Eu comecei academia em outubro do ano passado... E eu nunca tinha feito academia assim [...] e eu comecei pelo flag, por causa do flag, para ser um melhor jogador de flag [...] (ENTREVISTADO 1).

O terceiro entrevistado relata:

Desde a época que eu entrei no time, sempre procurei melhorar todas as técnicas e habilidades necessárias. Eu sou assíduo e evito perder treino [...] Mesmo nos treinos teóricos que são menos animados, eu procuro sempre ir (ENTREVISTADO 3). 
Gráfico 10: Carreira de lazer

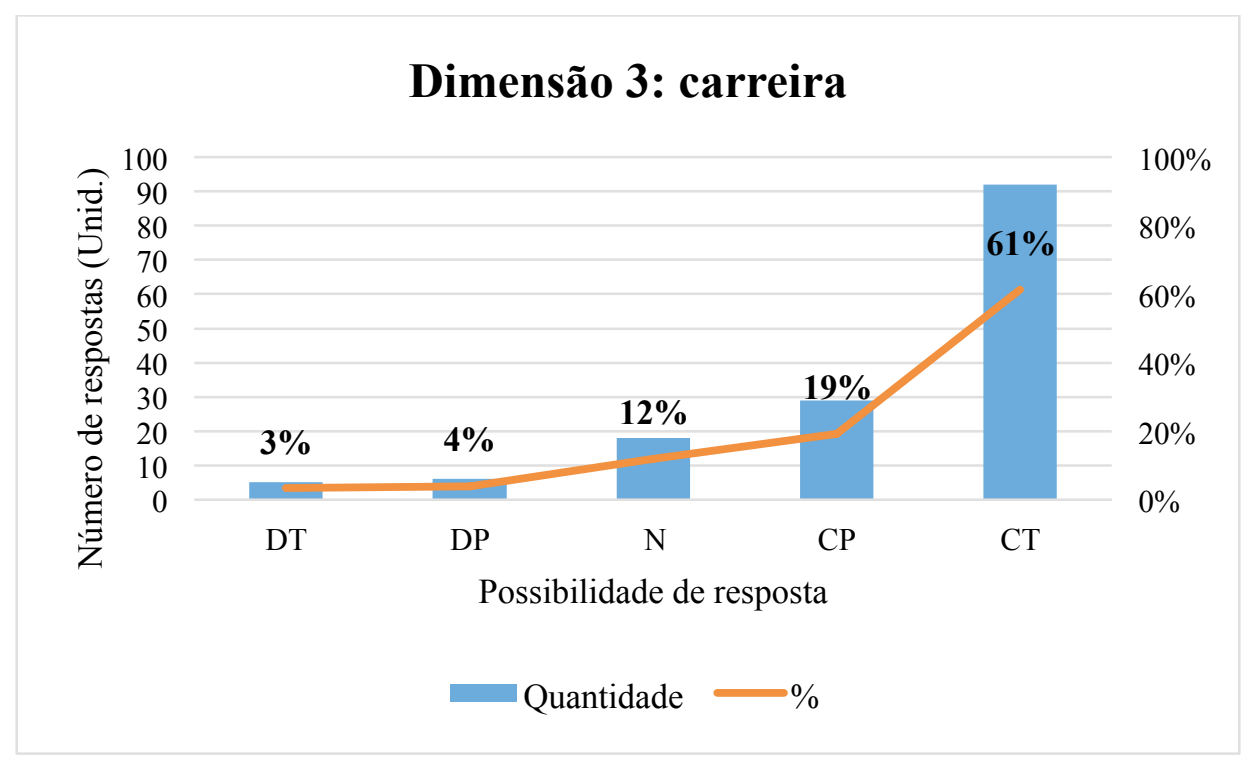

O décimo gráfico é a respeito da carreira e, as afirmações do inventário visaram definir se houve melhora de desempenho e se algum fator é determinante para o nível de envolvimento do voluntário na prática do LS. É possível verificar que $92 \%$ das respostas indicam que houve evolução dos atletas quanto às habilidades e capacidades necessárias para a prática, e isso se justifica pelo tempo investido em treinamento. Portanto, houve aqui a concordância com o que Gould et al. (2008) colocam sobre a carreira no LS, na qual o indivíduo percorre uma trajetória pessoal no seu desenvolvimento no LS e é modelado por contingências especiais, reviravoltas e diferentes níveis de realização e envolvimento:

É completamente diferente de quando você começa e sente a dificuldade de fazer uma recepção, uma rota ou jogar com a dinâmica do jogo. Então a evolução é muito clara [...] (ENTREVISTADO 2). 
Gráfico 11: Benefícios duráveis individuais

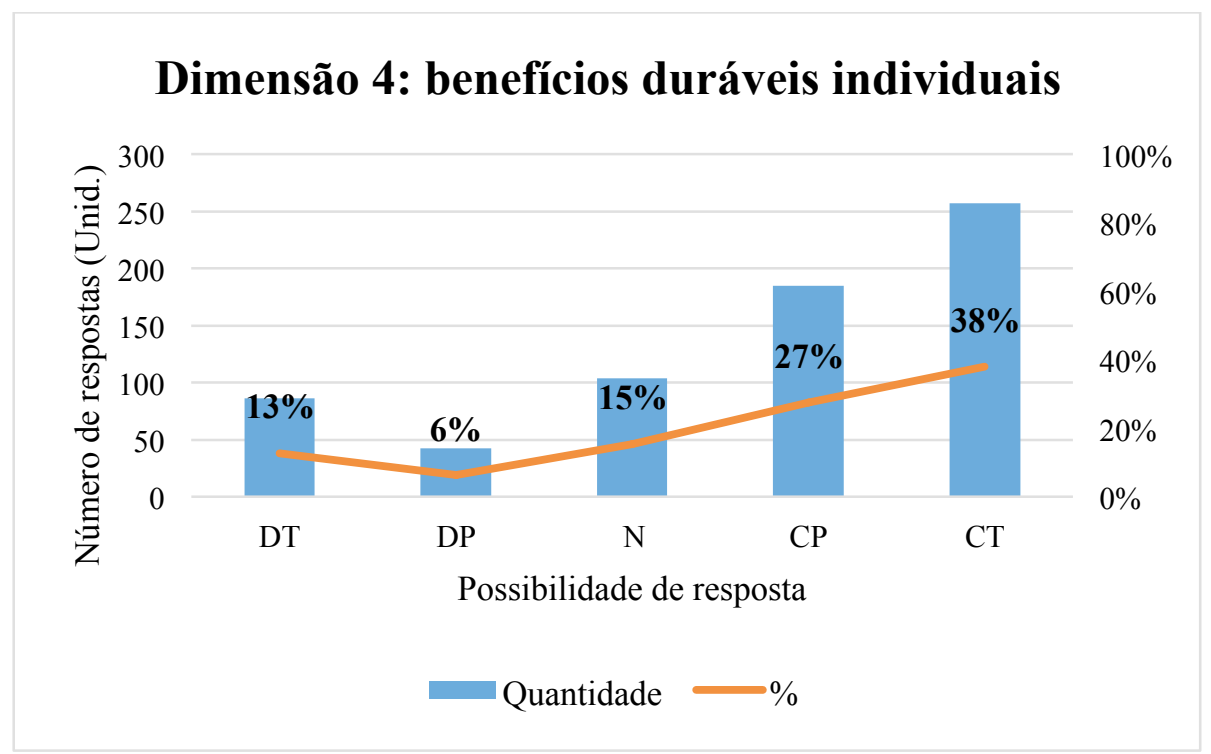

A quarta dimensão de benefícios duráveis foi dividida em dois gráficos. Gould et al. (2008) explicam que essa qualidade é avaliada para que se perceba a relação de custo-benefício da prática de LS na vida do indivíduo. Primeiro, será feita a análise dos benefícios individuais, que compreendem melhora de autoimagem, enriquecimento pessoal, recriação e outros. O gráfico demonstra que $65 \%$ das respostas dos atletas concordam que o flag favoreceu a realização pessoal por meio da melhora no sentimento de gratidão, satisfação, melhora da imagem pessoal, na forma de expressão individual e outros.

Hoje eu estou com quarenta anos e me sinto super bem. Dá para jogar numa boa, então eu me sinto sim, revigorado. Muitas vezes eu vejo um moleque de vinte anos cansado e eu ainda estou correndo. A própria modalidade em si é muito prazerosa. É um jogo que, quando dá certo e você consegue fazer a jogada, tem muita satisfação. Não só minha, mas do time inteiro (ENTREVISTADO 2).

Contudo, vale ressaltar que $13 \%$ das respostas se apresentam como totalmente discordantes devido aos itens relativos aos benefícios financeiros advindos do flag. 
Gráfico 12: Retorno financeiro

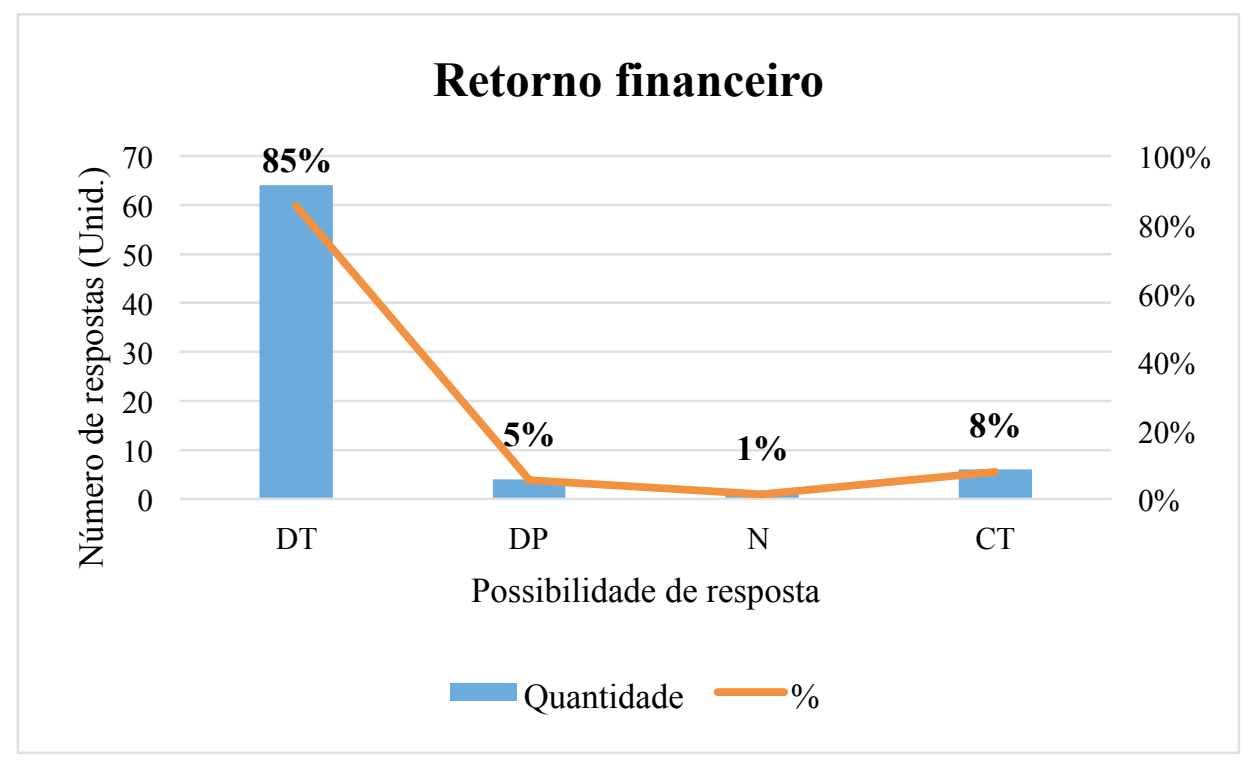

O gráfico 12 demonstra que, devido à organização do Eucalyptus Unicamp que se dá em torno de pagamento semestral dos atletas que fazem para se ter o direito de treinar e jogar, $85 \%$ das respostas discordam do recebimento de benefícios financeiros ou materiais. Gould et al. (2008) colocam que é possível que exista alguma recompensa material para os praticantes de LS embora isso não seja determinante para o envolvimento em LS.

Os entrevistados confirmam tais afirmações: “financeira é ao contrário. Porque gastamos muito dinheiro" (ENTREVISTADO 1); "Receber não. Somos voluntários aqui, e na verdade contribuímos financeiramente com o time" (ENTREVISTADO 3). 
Gráfico 13: Benefícios duráveis coletivos

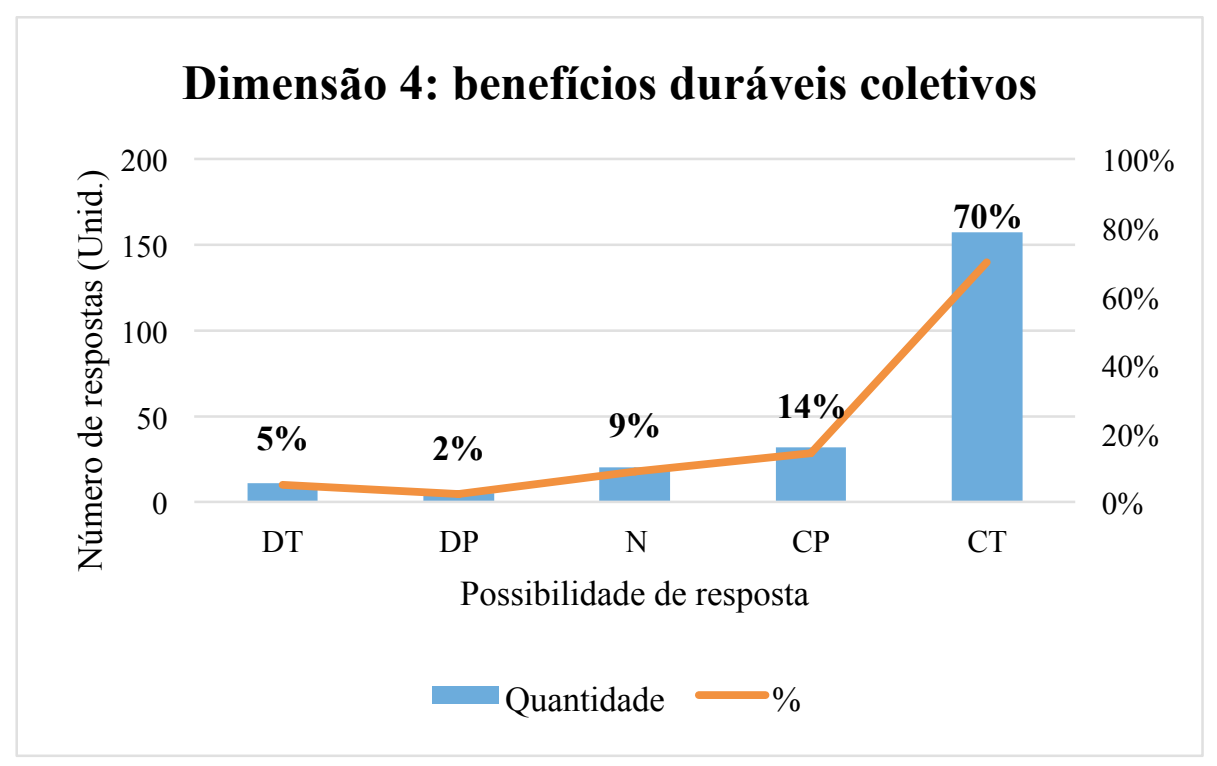

A segunda parte da dimensão sobre os benefícios duráveis são os benefícios coletivos, que compreendem atração e realização coletivas (GOULD et al., 2008). O gráfico indica que $84 \%$ das respostas apontam que na equipe existe uma boa interação entre os membros e que, de certa forma, isso demonstra coesão na busca do desenvolvimento do time.

Dentre os entrevistados, o relato do primeiro confirma:

Existe a interação dentro da equipe: somos muito amigos e muito unidos [...] todo mundo lá quer que os outros aprendam [...] nosso maior objetivo nos treinos, como equipe, é ganhar o campeonato e chegar longe. Esse é nosso foco desde o princípio e é uma satisfação muito grande [...] ano passado ganhamos a divisão e foi excelente! Comemoramos... Trabalhamos o ano inteiro para chegar naquilo (ENTREVISTADO 1).

O segundo concorda: 
É um jogo que ninguém faz nada sozinho. Ninguém se destaca sozinho. Para uma coisa dar certo é porque todo mundo fez dar certo, senão não acontece [...] é bem legal quando conseguimos uma vitória ou uma jogada. É um momento de realização e satisfação puras (ENTREVISTADO 2).

E o terceiro completa:

O time é bem unido, então não tem uma conquista individual. Sempre que ganhamos um jogo ou fazemos uma coisa boa, entendemos que o time conquistou aquilo. Eu me sinto unido ao time quando acontece uma coisa boa ou ruim (ENTREVISTADO 3).

Gráfico 14: Ethos único

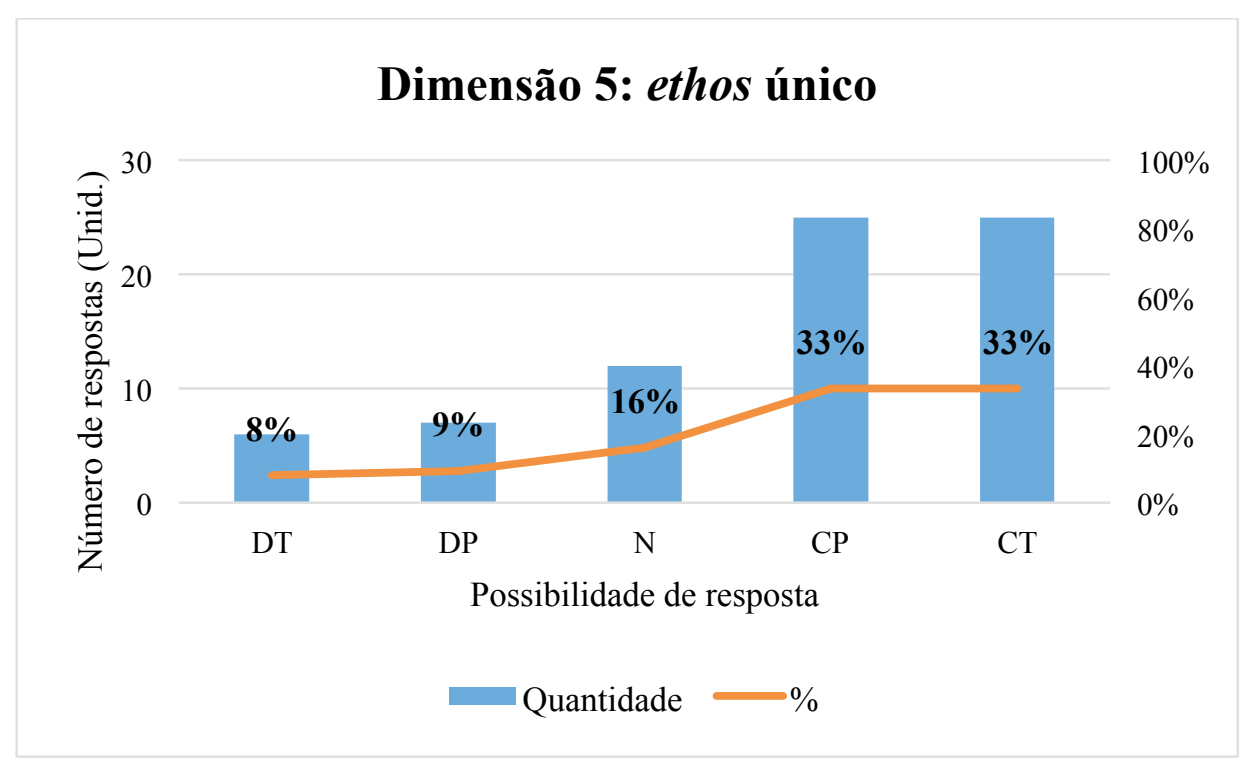

A dimensão representada pelo Gráfico 14 é sobre o Ethos Único, que avaliou se existe compartilhamento de ideais entre os atletas do mesmo time. Gould et al. (2008) explicam que no LS é possível que os membros de um grupo possam compartilhar crenças, valores, princípios morais, normas e, o mais importante para o caso dessa pesquisa, a busca por um desempenho de excelência. Assim, o gráfico indica que $66 \%$ das respostas são concordantes com o compartilhamento de ideais entre os atletas do time, contudo, $17 \%$ discordam dessa afirmação. Esse fato é interessante quando 
comparado a dimensão sobre os benefícios coletivos, onde cerca de $84 \%$ afirmaram que possuíam uma boa interação e coesão com os colegas de equipe.

Gráfico 15: Identificação com a prática de lazer

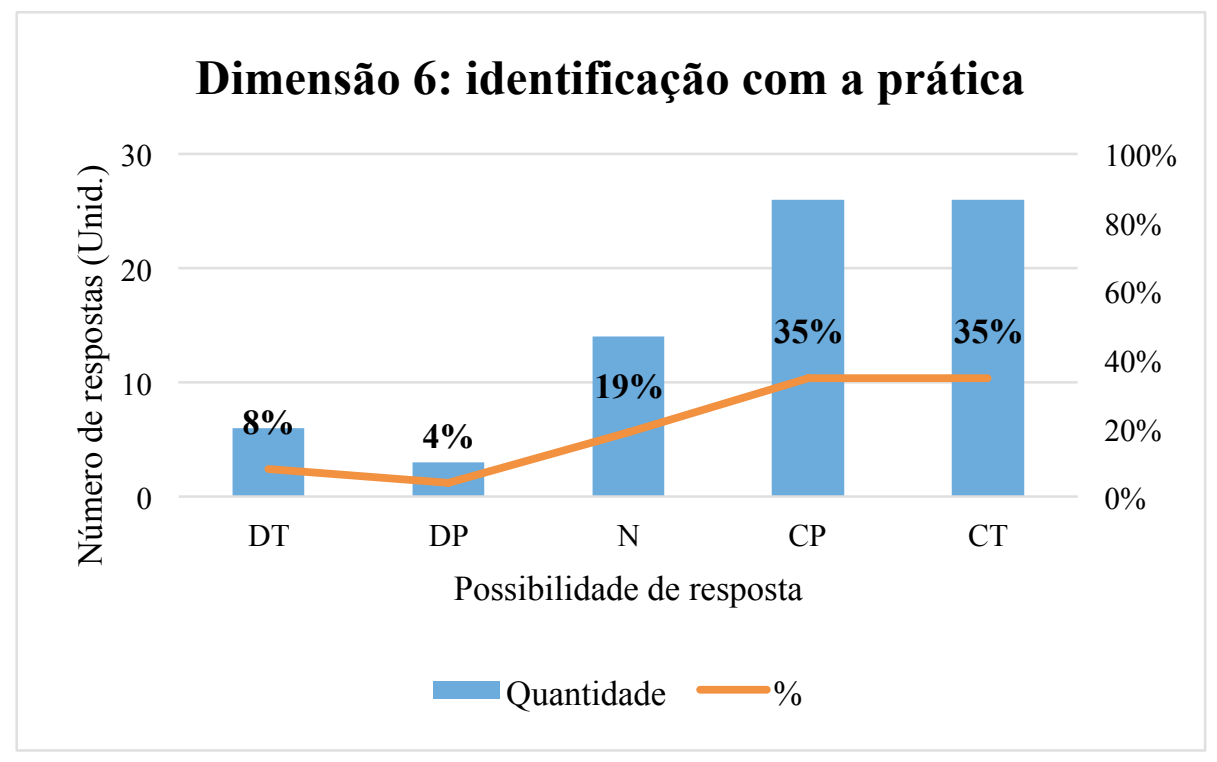

Para a última dimensão, da identificação com a prática, na qual foi verificado se os praticantes são reconhecidos como pessoas ligadas ao flag, 70\% das respostas concordam que eles são reconhecidos como praticantes de flag. Gould et al. (2008) discorrem que os participantes tendem a discursar com orgulho e animação sobre a atividade de LS, além de relatar para outras pessoas seus feitos de LS: "quem me conhece de perto, sabe. Porque eu falo disso toda hora ou estou indo a um treino" (ENTREVISTADO 1).

"Meus amigos mais próximos sabem que eu pratico flag. Porque a gente sempre fala disso. Também tem os posts da internet falando sobre como foi o jogo ou o treino" (ENTREVISTADO 2).

Porém, verifica-se que $31 \%$ das respostas discordam das afirmações. Isso se dá, pelo que também foi levantado nas entrevistas: o flag ainda é uma modalidade 
desconhecida, fato que não deixa claro aos leigos, qual é o esporte vivenciado pelos voluntários desta pesquisa.

O primeiro entrevistado afirma:

Quem não me conhece muito bem, acha que eu jogo rúgbi ou futebol americano. Não entendem muito bem o flag, porque não é um esporte muito comum (ENTREVISTADO 1).

O terceiro entrevistado relata:

Algumas pessoas, quando ouvem falar de futebol americano, lembram que eu jogo alguma coisa relacionada ao futebol americano. Mas é bem pouco, e acho que é assim porque poucas pessoas conhecem o flag [...] embora esteja se tornando mais conhecido, o flag não é divulgado. Se você perguntar para os meus amigos o que você acha de flag, eles não vão nem fazer ideia do que se trata (ENTREVISTADO $3)$.

Gráfico 16: Pontuação de cada voluntário

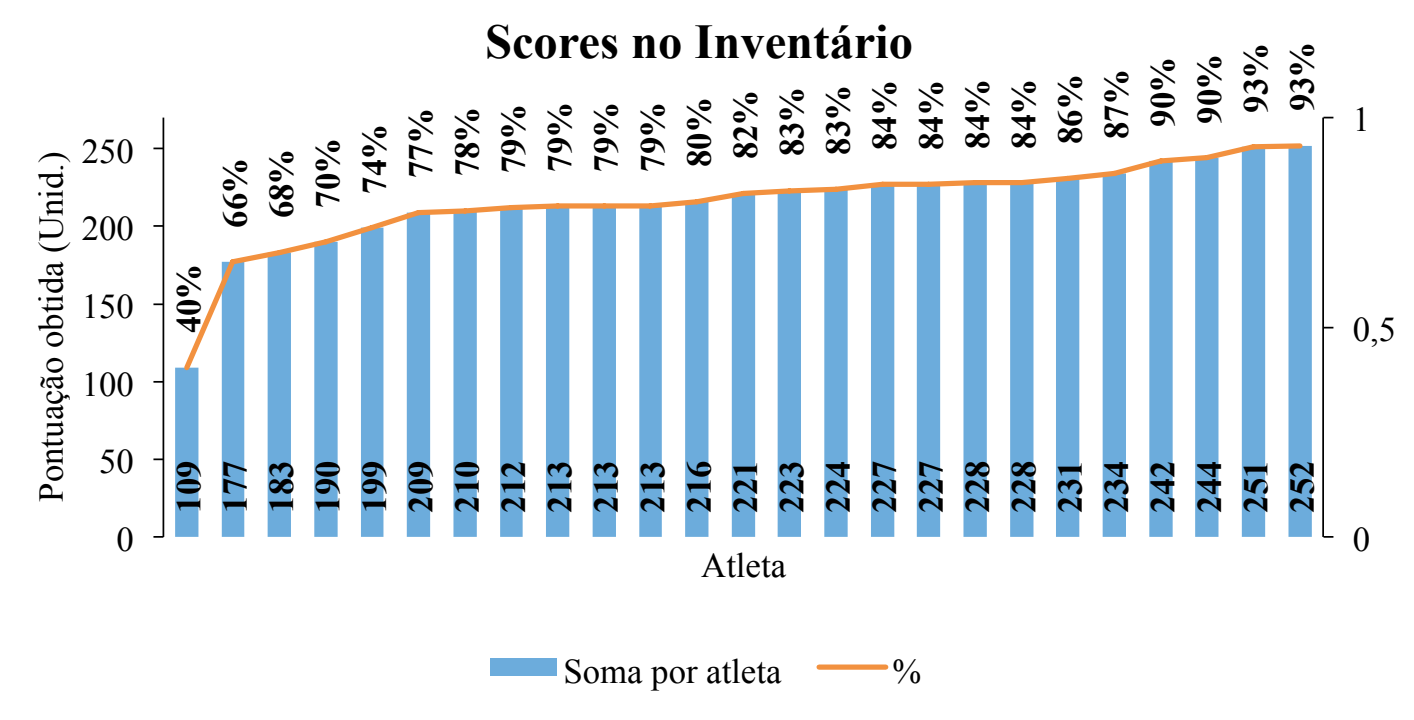

O último gráfico representa a soma das pontuações de cada voluntário dessa pesquisa. De um máximo de 270 pontos, é possível verificar que os atletas alcançaram altos escores e, por consequência, cumprem os requisitos avaliados nas dimensões do 
LS levantadas por Stebbins (2016) por meio do Inventário de Medidas em Lazer Sério de Gould e colaboradores (2008).

Além disso, é possível se compreender a importância do flag na vida dos atletas. Nas entrevistas, os participantes relatam que o flag é um elemento central em suas rotinas - compromissos são reagendados, lesões são superadas, os treinos são indispensáveis, o grupo é prioridade e esforços extra treino são comuns.

Para o entrevistado 1:

O flag traz fortes emoções [...] na maior parte do tempo ele é um ponto muito positivo na minha vida. Às vezes eu até sonho, sabe? "Vou fazer uma jogada no campeonato ou vou voltar no ônibus fazendo zona". Isso é muito bom, muito bom! É uma terapia (ENTREVISTADO 1).

O segundo entrevistado relata:

Eu acho que é uma realização pessoal de várias formas. Uma realização pessoal no aspecto físico, de você conseguir praticar essa modalidade aos 40 anos. É uma realização em poder praticar algo distante e impossível, que só existia nos Estados Unidos [..] depois eu vi que não! Que tinha aqui do lado e era real! [...] nessa questão social de você fazer parte de um grupo e estar em contato com pessoas diferentes, de outra geração, de outras idades e tal. É bem bacana e bem significativo. O flag é na minha vida é bem significativo. Hoje mesmo, a minha esposa falou antes de eu vir para cá: "nossa, o flag está tomando um espaço grande na sua vida, né? Eu só não reclamo porque eu sei que você adora isso, então não tem problema. Vai lá". Então é isso. Quem gosta se envolve e ele vai tomando conta. (ENTREVISTADO 2) (sic).

Gould et al. (2008), descrevem que as atividades sérias podem aliviar a sensação de tédio, além de desfazer a ideia de que a vida de um indivíduo se desenvolve sem nenhum tipo de excitação significativa. Além disso, afirmam que o LS na sociedade pós-moderna é considerado uma busca de sentido e identidade, porque o indivíduo quer estabelecer relações com uma comunidade, ter sentimento de pertencimento a um grupo e ter um estilo de vida coerente com os princípios da prática. 


\section{Considerações Finais}

Visto os objetivos desta pesquisa, que foram verificar, por meio do Inventário de Medidas em Lazer Sério (GOULD et al., 2008), se os atletas da equipe Eucalyptus Unicamp se envolvem com a modalidade flag como lazer sério e, descrever a importância do esporte na vida dos participantes, pode-se afirmar que eles apresentam as qualidades distintivas do lazer sério propostas por Stebbins (1999). Isso se demonstrou no modo como tais atletas se relacionam com o esporte e na forma significativa e determinante que o flag é central na organização de rotinas e prioridades de vida.

Além disso, é possível assegurar que o flag já se adaptou à realidade brasileira, com o advento da versão $8 \times 8$, ademais a modalidade tem potencial para se popularizar e crescer devido à facilidade da prática e da semelhança com o futebol americano, que atrai cada vez mais público devido às transmissões televisivas.

Os resultados desse trabalho contribuem para a discussão do lazer no Brasil e, em especial, coloca a Perspectiva do Lazer Sério como um viés importante para a compreensão da vivência do esporte universitário da Unicamp, na qual é possível que os alunos atletas vivenciem o esporte com compromisso e esforço. Certamente, esse referencial teórico também pode auxiliar outros estudos sobre esporte universitário como possibilidade de lazer em outras universidades brasileiras.

Uma limitação deste estudo foi não ter havido explicação prévia para os atletas sobre o que cada conceito das dimensões significava, o que pode ter feito com que as respostas obtidas não fossem as mais próximas à realidade. Por outro lado, as entrevistas detalharam qualitativamente essas dimensões, às quais, o seu uso em estudos futuros mostrou-se importante para complementar os resultados obtidos no inventário. 


\section{REFERÊNCIAS}

ASSOCIAÇÃO PRÓ-FUTEBOL AMERICANO - APFA. Livro de Regras do Campeonato Paulista de Flag 2016. [s.1.:s.n.] Versão 1.1. 2016.

BARDIN, L. Análise de conteúdo. São Paulo: Edições 70, 2011.

BITTENCOURT, Valéria; AMORIM, Simone. Flag Football e Futebol Americano. Atlas do Esporte no Brasil. Rio de Janeiro: CONEF, 2006.

CURTI, Anthony. Manual do futebol americano. Santos: Simolsen, 2016

FOOTBALL BABBLE. Flag Football History. Disponível em: http://www.footballbabble.com/football/flag/history . Acesso em: 16 jan. 2016.

GOMES, Christianne Luce. Metodologia da pesquisa aplicada ao lazer. Brasília: SESI/DN, 2005.

GOULD, James et al. Development of the Serious Leisure Inventory and Measure. Journal of Leisure Research, v. 40, n. 1, p. 47-68. 2008.

LAU, Liga das Atléticas da UNICAMP. Projeto Seleções 2015. Acervo Pessoal. Impresso. 2015.

LEVIN, Jack. Estatística Aplicada a Ciências Humanas. 2. ed. São Paulo: Harbra, 1987.

MARCONI, Marina de Andrade. LAKATOS. Eva Maria. Técnicas de pesquisa: planejamento e execução de pesquisas, amostragens e técnicas de pesquisas, elaboração, análise e interpretação de dados. 5. ed. São Paulo: Atlas, 2002.

MERLO, Thiago. Prática e desenvolvimento do futebol americano de praia no Estado do Rio de Janeiro. In: MOSTRA CIENTÍFICA DE EDUCAÇÃO FÍSICA DA UNIVERSIDADE CASTELO BRANCO, 1., 2005. Rio de Janeiro. Anais... Rio de Janeiro, 2005.

MINAYO, Maria Cecília. (Org.); GOMES, S. F. D. R.; GOMES, R. Pesquisa social: teoria, método e criatividade. 31. ed. Petrópolis: Vozes, 2012.

OLIVEIRA, Saulo Neves. DOLL, Johannes. Serious Leisure. Movimento. Porto Alegre, v. 18, n. 01, p. 325-338, jan/mar de 2012.

PERFEITO, Rodrigo et al. Apresentação do Flagfootball como possibilidade pedagógica. Revista Augustus. Rio de Janeiro, v.17, n.34, jul/2012.

SILVA, Severino Domingos. COSTA, Francisco José. Mensuração e Escalas de Verificação: uma Análise Comparativa das Escalas de Likert e Phrase Completion. 
Revista Brasileira de Pesquisas de Marketing, Opinião e Mídia, São Paulo, v. 15, p. $1-16$, out de 2014.

SOUZA, Luciano Teixeira de. O Esporte Universitário e a Motivação do Aluno Unicamp na Prática de Atividades Físicas e Esportivas. Trabalho de Conclusão de Curso (Graduação) - Faculdade de Educação Física. Universidade Estadual de Campinas, Campinas, 2006.

STEBBINS, Robert. Amateurs: On the Margin Between Work and Leisure. [1979]

STEBBINS, Robert. Educating for serious leisure: education in theory and practice. World Leisure and Recreation, 41, p.14-19. 1999.

- Dumazedier, the serious leisure perspective and leisure in Brazil. World Leisure Journal, v. 58, n. 3, p. 151-161, DOI: 10.1080/16078055.2016.1158205.

UNICAMP NOTÍCIAS. Unicamp Eucalyptus inicia preparativos para disputar paulista de futebol. Disponível em: http://www.unicamp.br/unicamp/noticias/2017/02/16/unicamp-eucalyptus-iniciapreparativos-para-disputar-paulista-de-futebol> Acesso em: 17 fev. 2017.

\section{Endereço das Autoras:}

Bianca Inácio da Luz Ferreira

Rua Galileia, 265 - Bosque dos Eucaliptos

São José dos Campos - SP - 12.233-250

Endereço Eletrônico: biailf@gmail.com

Olívia Cristina Ferreira Ribeiro

Avenida Érico Veríssimo, 701 - Barão Geraldo

Campinas - SP - 13.083-851.

Endereço Eletrônico: olivia@fef.unicamp.br 